\title{
Herbicidas no controle de Chloris distichophylla (Falso-capim-de-rhodes)
}

\author{
Herbicides to control Chloris distichophylla (False-Star-Grass)
}

\author{
Anderson Luis Nunes ${ }^{1}$, Ribas Antonio Vidal ${ }^{2}$, Michelangelo Muzzel Trezzi ${ }^{3}$, \\ Augusto Kalsing ${ }^{4}$, Ives Clayton Gomes dos Reis Goulart ${ }^{4}$
}

\begin{abstract}
Resumo - O falso-capim-de-rhodes (Chloris distichophylla) tem sido selecionado em áreas de fruticultura e soja transgênica no Rio Grande do Sul, em função de sua possível tolerância ao herbicida glyphosate. Esta seleção ocorre devido à utilização intensa deste herbicida nestes sistemas de cultivo, o que acarreta em elevada pressão de seleção do herbicida sobre as plantas tolerantes. O objetivo deste trabalho foi avaliar a eficácia de herbicidas pertencentes a diferentes mecanismos de ação no controle do falso-capim-de-rhodes e a possível tolerância desta espécie em três estádios de desenvolvimento ao herbicida glyphosate. Foram realizados três experimentos em casa de vegetação na Faculdade de Agronomia da UFRGS, em Porto Alegre - RS, utilizandose o delineamento experimental inteiramente casualizado e quatro repetições por tratamento. Pode-se verificar que, nos estádios de 4, 8 e 15 folhas, o falso-capim-de-rhodes não foi tolerante ao glyphosate. Ainda, no estádio de 4 folhas, os herbicidas atrazine, glufosinate, glyphosate e paraquat apresentam controle eficaz e os herbicidas fluazifop, imazapyr e mesotrione apresentaram apenas controle satisfatório.
\end{abstract}

Palavras-chave: Controle químico, tolerância, plantas daninhas

\begin{abstract}
The weed Chloris distichophylla (Lag) has been selected in areas of orchards and RR soybean in the Rio Grande do Sul- RS (Brazil), resulting of its possible tolerance to the herbicide glyphosate. This selection occurs due to intense use of this herbicide in the last years resulting in a disturb caused by the high pressure selection imposed by the herbicide occurs, resulting in selection of tolerant plants. The objective of this study was to evaluate the effectiveness of herbicides pertaining the different mechanisms of action in the control of the Chloris distichophylla and the possible tolerance of this species in three growth stages to the glyphosate herbicide. Three experiments were carried out in the College of Agronomy of the UFRGS in Porto Alegre - RS (Brazil) through the experimental design completely randomized with four replications. $C$. distichophylla in early growth stages was not tolerant to glyphosate. Moreover, the atrazine, glufosinate, glyphosate and paraquat herbicides showed high control
\end{abstract}

\footnotetext{
${ }^{1}$ Eng. Agr., M.S., Professor do Instituto Federal do Rio Grande do Sul - Campus Sertão, Rodovia RS 135, Km 25,

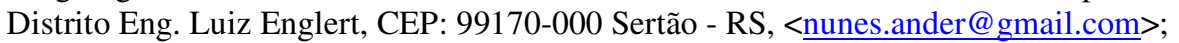

2 Eng. Agr., Ph.D., Professor da Universidade Federal do Rio Grande do Sul - UFRGS, Caixa Postal 15.100, 90000970 Porto Alegre-RS, bolsista do CNPq, <ribas.vidal@ufrgs.br>;

${ }^{3}$ Eng. Agr., Dr., Prof. da Universidade Tecnológica Federal do Paraná, Caixa Postal 571, 85503-390 Pato BrancoPR, <trezzi@utfpr.br>;

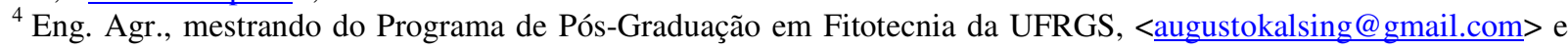
<ivesclayton@gmail.com>.
}

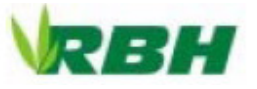


when the weed had four leafs, whereas the fluazifop, imazapyr and mesotrione herbicides had showed satisfactory control.

Key-words: chemical control, tolerance, weed plant.

\section{Introdução}

O gênero Chloris é pouco conhecido e apresenta um grande número de plantas distribuídas por regiões tropicais e subtropicais dos diversos continentes. Dentre essas, muitas ocorrem no Brasil de forma nativa, sendo que a espécie Chloris gayana foi introduzida como forrageira. A espécie Chloris distichophylla (Lag) (sinonímia: Eustachys distichophylla) diferencia-se das outras plantas de seu gênero, pela presença de lema fértil com dorso glabro e com abundantes e grandes cílios marginais. Possui o antécio estéril lanceolado, com 1,6 a $2,2 \mathrm{~mm}$, com racemos especiformes flexuosos, com 8,0 a $15,0 \mathrm{~cm}$ de comprimento em número de 10 a 35 e o antécio fértil com 2,5 a $3,0 \mathrm{~cm}$. Sua altura varia entre 0,7 a $1,4 \mathrm{~m}$ de altura, com base dística e geralmente violácea (Kissmann \& Groth, 1992).

A espécie $C$. distichophylla tem sido selecionada em áreas de fruticultura e soja transgênica no Rio Grande do Sul, em função de sua possível tolerância ao glyphosate. Esta seleção ocorre devido à utilização intensa deste herbicida nestes sistemas de cultivo, o que acarreta em elevada pressão de seleção do herbicida sobre as plantas tolerantes. Destacase que a seleção de plantas tolerantes pode ocorrer com qualquer herbicida.

Esta espécie pode comportar-se como pioneira, tornando-se dominante em lavouras abandonadas. Fazem parte do grupo de plantas com ciclo de assimilação de $\mathrm{CO}_{2}$ via $\mathrm{C} 4$, o que significa altas taxas de fotossíntese, altos valores de saturação de luz e altas temperaturas para crescimento (Maraschin, 1995). Porém, suporta geadas fracas, secas e salinidade do solo. Apresenta fácil estabelecimento e a produção de sementes é elevada (Tamissia et al., 2001).
A seleção de espécies tolerantes ocorre quando se utilizam sucessivamente os mesmos herbicidas ou herbicidas diferentes com mesmo mecanismo de ação (Menezes et al., 2009). A tolerância é resultado da capacidade inata da espécie em suportar aplicações de herbicidas, nas doses recomendadas, sem alterações marcantes em seu crescimento e desenvolvimento. A tolerância leva à seleção natural das plantas daninhas sobre as quais o produto tiver efeito reduzido. Já a suscetibilidade, também, é uma característica inata de uma espécie, mas há alterações com efeitos marcantes no crescimento e desenvolvimento da planta, como resultado da falta de capacidade de suportar a ação do herbicida (Christoffoleti et al., 2000).

Apesar de o glyphosate ser um herbicida não seletivo, nos últimos anos têm-se verificado algumas espécies de plantas daninhas tolerantes às doses recomendadas desse produto.

No Brasil, a tolerância ao glyphosate tem sido detectada em Commelina benghalensis, Commelina virginica, Commelina diffusa, (Durigan et al., 1988; Ramos \& Durigan, 1996; Santos et al., 2001), Ipomoea grandifolia e Richardia brasiliensis (Monquero \& Christoffoleti, 2003). Os mecanismos de tolerância comprovados incluem a absorção e translocação diferencial, local de ação alterado e compartimentalização de glyphosate (Monquero et al., 2004; Koger \& Reddy, 2005, Veline et al., 2009).

O paraquat é um herbicida não seletivo, pertencente ao grupo dos bipiridilos, amplamente utilizado em culturas como fumo, algodão, arroz, café, cana-de-açúcar, feijão, maçã, soja, uva, não apresentando persistência 
residual no solo (Almeida \& Rodrigues, 1985; Peter et al., 1992).

$\mathrm{O}$ atrazine pertence ao grupo químico das triazinas, inibidor do transporte de elétrons no FSII (Fuerst \& Norman, 1991), sendo utilizado mais amplamente no controle seletivo em pré-emergência ou pós-emergência inicial das plantas daninhas dicotiledôneas e de algumas gramíneas no milho e em outras culturas (Rizzardi et al., 2004).

O objetivo deste trabalho foi avaliar a eficácia de herbicidas pertencentes a diferentes mecanismos de ação no controle do falsocapim-de-rhodes e a possível tolerância desta mecanismos de ação.

\begin{tabular}{lccc}
\hline Mecanismo de ação & $\begin{array}{c}\text { Ingrediente Ativo ou } \\
\text { Equivalente Ácido }\end{array}$ & $\begin{array}{c}\text { Concentração } \\
\mathrm{g} \mathrm{kg}^{-1} \text { ou g L}\end{array}$ & g p.c. ha \\
\hline Inibidores de ACCase & clethodim & 240 & 108 \\
& fluazifop & 125 & 250 \\
Inibidores de ALS & metsulfuron & 600 & 4 \\
Inibidor de EPSPS & imazapyr & 250 & 750 \\
Inibidor de FS1 & glyphosate & 360 & 2160 \\
Inibidor de PROTOX & paraquat & 200 & 400 \\
Inibidor de Parede celular & lactofen & 240 & 180 \\
Inibidor de Glutamina sintase & quinclorac & 500 & 375 \\
Inibidor de FS2 & glufosinate & 200 & 600 \\
Inibidor de Caroteno & atrazine & 400 & 2400 \\
Outros & mesotrione & 480 & 144 \\
& propanil & 360 & 3600 \\
\hline
\end{tabular}

- Em todos os tratamentos foi adicionado surfactante Extravon na dose de 0,25\% do volume de calda.

A aplicação dos herbicidas foi um volume de calda de 100 L.ha ${ }^{-1}$. No realizada quando as plântulas apresentavam 5 momento das aplicações a temperatura $\mathrm{cm}$ e de altura e quatro folhas completamente ambiente variou entre 20 e $26^{\circ} \mathrm{C}$, a umidade expandidas, que variou entre 50 e 63 dias após relativa do ar variou entre 76 e 86\%. Os vasos a emergência. A aplicação foi realizada com foram irrigados por capilaridade, sendo pulverizador pressurizado com $\mathrm{CO}_{2}$ colocados em bandejas com uma lâmina d'água comprimido na pressão de $200 \mathrm{kPa}$, com ponta de $10 \mathrm{~mm}$ de altura. Os tratamentos utilizados de pulverização modelo 110.01 e utilizando-se 
Nunes, A.L. et al.

nos trabalhos e suas dosagens encontram-se na Tabela 1.

No primeiro experimento foram realizadas avaliações visuais de fitotoxicidade aos 06, 12 e 18 dias após a aplicação dos herbicidas (DAA). No segundo e terceiro experimentos foram realizadas avaliações visuais de fitotoxicidade aos $03,06,09,12,15$, 18 e 21 DAA. A avaliação de fitotoxicidade foi baseada no vigor e clorose da planta, comparada com a testemunha, sendo atribuído $0 \%$ quando não existia injúria e $100 \%$ quando havia controle total das plantas pelos herbicidas. $\mathrm{O}$ controle foi considerado satisfatório quando maior ou igual a $80 \%$, intermediário de 50 a $75 \%$ e insatisfatório quando menor que 50\% (Frans et al., 1986). No terceiro experimento, os herbicidas glyphosate e quinclorac foram aplicados em plantas de falso-capim-de-rhodes em três estágios de desenvolvimento, referente às plantas apresentarem 4, 8 e 15 folhas.

Os resultados coletados foram inicialmente submetidos à análise de variância através do teste F. Quando constatadas diferenças significativas, foi realizado o teste de comparação de médias pelo teste de DMS ao nível de $5 \%$ de probabilidade do erro experimental.

\section{Resultados e discussão}

\section{Primeiro experimento}

Aos 6 DAA, o controle químico de $C$. distichophylla variou entre 1 a $100 \%$ (Tabela 2). O melhor resultado foi obtido com o herbicida paraquat, controlando $100 \%$ das plantas testadas. Este é um herbicida inibidor do FS 1, não seletivo, responsável pela peroxidação das membranas celulares. (Merotto Jr. \& Fleck, 2001). O herbicida propanil obteve $73 \%$ de controle das plantas e diferiu estatisticamente do herbicida paraquat.
O propanil é um herbicida inibidor fotossintético. Os herbicidas paraquat e propanil obtiveram um alto efeito inicial em função da sua ação de contato, não necessitando de translocação no interior da planta como os herbicidas sistêmicos para ocasionarem injúrias às plantas. Os outros tratamentos obtiveram controle insatisfatório até aos 6 DAA, não ultrapassando $17 \%$.

Aos 12 DAA, o nível geral de controle aumentou, devido à ação superior dos herbicidas sistêmicos. Esta reação já era esperada, pois, estes necessitam de um período para a translocação do herbicida no interior da planta (Tabela 2). Neste período, o nível de controle do herbicida propanil passou de 73 para $88 \%$, não mais diferindo do herbicida paraquat, que manteve $100 \%$ de controle. O herbicida glufosinate não diferiu estatisticamente do herbicida propanil, atingindo o nível de controle de 67\%. O glufosinate é um inibidor da glutamina sintase, inibindo o metabolismo do nitrogênio ocasionando o acúmulo de amônia e posterior morte da planta (Christoffoleti et al., 2004).

Aos 18 DAA, os herbicidas paraquat, propanil, glufosinate, atrazine, glyphosate e fluazifop, não diferiram estatisticamente entre si, obtendo 100, 100, 98, 98, 92 e $85 \%$ de controle, respectivamente (Tabela 2). A atrazine é um inibidor da FS 2 (Tabela 1), do grupo das triazinas, que se acopla ao componente QB do sistema fotossintético e assim impossibilita a ocorrência de transporte de elétrons até a plastoquinona (Fleck \& Vidal, 2001). O herbicida glyphosate é inibidor de EPSPs que age sobre a enzima enol-piruvilshikimato-fosfate sintetase (EPSPs), responsável por uma das etapas da síntese de aminoácidos (Trezzi et al., 2001). Já o fluazifop pertence aos inibidores da ACCase, do grupo químico das ariloxifenoxipropionatos que inibe a enzima ACCase responsável pela síntese de ácidos graxos (Vidal \& Merotto Jr., 2001). O clethodim, também inibidor de ACCase, mas do grupo químico da 
ciclohexanodionas, apresentou controle de apenas 10\%. O mesotrione obteve controle intermediário de $75 \%$, não diferindo dos herbicidas glyphosate e fluazifop. O lactofen (inibidor da PROTOX), o imazapyr e o metsulfuron (inibidores da ALS) e, o quinclorac (inibidor da Parede Celular) e o ácido acético apresentaram controle insatisfatório. Cabe destacar que as plantas aspergidas com quinclorac apresentaram estímulo no seu desenvolvimento em relação à testemunha.

Tabela 2 - Controle de Chloris distichopylla, na média de três repetições, no estádio de quatro folhas com herbicidas pertencentes a diferentes mecanismos de ação.

\begin{tabular}{lcrrr}
\hline Herbicida & g i.a ha $^{-1}$ & $6 \mathrm{DAA}^{1}$ & 12 DAA & 18 DAA \\
\hline Atrazine & 960,0 & $7 \mathrm{defg}$ & $50 \mathrm{~cd}$ & $98 \mathrm{a}$ \\
Clethodim & 026,0 & $13 \mathrm{~cd}$ & $12 \mathrm{fg}$ & $10 \mathrm{cde}$ \\
Fluazifop & 031,2 & $5 \mathrm{defg}$ & $3 \mathrm{fg}$ & $85 \mathrm{ab}$ \\
Glufosinate & 120,0 & $12 \mathrm{cde}$ & $67 \mathrm{bc}$ & $98 \mathrm{a}$ \\
Glyphosate & 778,0 & $12 \mathrm{cde}$ & $22 \mathrm{efg}$ & $92 \mathrm{ab}$ \\
Imazapyr & 187,0 & $17 \mathrm{c}$ & $17 \mathrm{efg}$ & $23 \mathrm{~cd}$ \\
Mesotrione & 550,0 & $10 \mathrm{cdef}$ & $42 \mathrm{cde}$ & $75 \mathrm{~b}$ \\
Metsulfuron & 002,4 & $2 \mathrm{fg}$ & $3 \mathrm{fg}$ & $3 \mathrm{de}$ \\
Propanil & 129,6 & $73 \mathrm{~b}$ & $88 \mathrm{ab}$ & $100 \mathrm{a}$ \\
Quinclorac & 187,5 & $1 \mathrm{~g}$ & $0 \mathrm{~g}$ & $0 \mathrm{e}$ \\
Ácido Acético & $5 \%$ & $5 \mathrm{defg}$ & $3 \mathrm{fg}$ & $3 \mathrm{de}$ \\
Testemunha & 0 & $0 \mathrm{~g}$ & $0 \mathrm{~g}$ & $0 \mathrm{e}$ \\
\hline Média Geral & & 18,57 & 31,19 & 51,42 \\
CV $(\%)^{3}$ & 28,78 & 48,97 & 23,76 \\
DMS 5\% & 8,94 & 25,56 & 20,45 \\
\hline
\end{tabular}

- Dias após a aplicação do herbicida;

2 - Médias seguidas pela mesma letra minúscula não diferem entre si pelo teste DMS a 5\%;

3 - Coeficiente de variação.

Apesar de C. distichophylla ser tolerante ao herbicida glyphosate, o mesmo controlou $92 \%$ das plantas com 4 folhas aos 18 DAA. Isto se deve ao fato do herbicida ser aplicado em estádio de desenvolvimento inicial, tornando-se assim uma alternativa de controle.

\section{Segundo experimento}

O efeito dos herbicidas nesta avaliação foi semelhante ao primeiro experimento. Somente o imazapyr, que no primeiro trabalho apresentou $23 \%$ de controle aos 18 DAA, atingiu aproximadamente $82 \%$ de controle no segundo experimento. Paraquat, aos 3 DAA, causou $83 \%$ de toxicidade nas plantas de falsocapim-de-rhodes e aos 6 DAA obteve 100\% da mesma, mantendo-a até o fim do experimento (Tabela 3). Aos 9 DAA, os compostos glufosinate, glyphosate e mesotrione apresentaram controle satisfatório $(\geq 80 \%)$, mas ainda estatisticamente inferior ao do paraquat. Aos 12 DAA, os tratamentos atrazine, glufosinate, glyphosate não diferiram do paraquat e apresentaram o mesmo nível de intoxicação às plantas aspergidas, com controle médio acima de 95\%. Aos 18 e 21 DAA, o herbicida propanil também não diferiu do paraquat e apresentou elevado controle das plantas. Ao final do experimento, os herbicidas fluazifop, imazapyr e mesotrione apresentaram 
Nunes et al.

toxicidade satisfatória, mas menor em relação e paraquat. aos compostos atrazine, glufosinate, glyphosate

Tabela 03 - Toxicidade dos herbicidas utilizados em função do período após a aplicação dos herbicidas.

\begin{tabular}{lccccccc}
\hline Tratamentos & $3 \mathrm{DAA}$ & $6 \mathrm{DAA}$ & $9 \mathrm{DAA}$ & $12 \mathrm{DAA}$ & $15 \mathrm{DAA}$ & $18 \mathrm{DAA}$ & $21 \mathrm{DAA}$ \\
\hline Atrazine & $13 \mathrm{e}^{1}$ & $45 \mathrm{de}$ & $78 \mathrm{bc}$ & $95 \mathrm{ab}$ & $100 \mathrm{a}$ & $100 \mathrm{a}$ & $100 \mathrm{a}$ \\
Fluazifop & $23 \mathrm{~cd}$ & $38 \mathrm{e}$ & $48 \mathrm{~d}$ & $63 \mathrm{e}$ & $77 \mathrm{e}$ & $83 \mathrm{~b}$ & $83 \mathrm{~b}$ \\
Glufosinate & $0 \mathrm{f}$ & $47 \mathrm{~cd}$ & $87 \mathrm{~b}$ & $95 \mathrm{ab}$ & $98 \mathrm{ab}$ & $98 \mathrm{a}$ & $98 \mathrm{a}$ \\
Glyphosate & $27 \mathrm{c}$ & $53 \mathrm{c}$ & $87 \mathrm{~b}$ & $98 \mathrm{a}$ & $100 \mathrm{a}$ & $98 \mathrm{a}$ & $95 \mathrm{a}$ \\
Imazapyr & $23 \mathrm{~cd}$ & $38 \mathrm{e}$ & $40 \mathrm{~d}$ & $73 \mathrm{~d}$ & $85 \mathrm{~d}$ & $82 \mathrm{~b}$ & $82 \mathrm{~b}$ \\
Mesotrione & $0 \mathrm{f}$ & $42 \mathrm{de}$ & $80 \mathrm{~b}$ & $88 \mathrm{bc}$ & $90 \mathrm{c}$ & $85 \mathrm{~b}$ & $82 \mathrm{~b}$ \\
Paraquat & $83 \mathrm{a}$ & $100 \mathrm{a}$ & $100 \mathrm{a}$ & $100 \mathrm{a}$ & $100 \mathrm{a}$ & $100 \mathrm{a}$ & $100 \mathrm{a}$ \\
Propanil & $55 \mathrm{~b}$ & $63 \mathrm{~b}$ & $70 \mathrm{c}$ & $87 \mathrm{c}$ & $95 \mathrm{~b}$ & $97 \mathrm{a}$ & $95 \mathrm{a}$ \\
Quinclorac & $18 \mathrm{de}$ & $2 \mathrm{f}$ & $2 \mathrm{e}$ & $2 \mathrm{f}$ & $2 \mathrm{f}$ & $2 \mathrm{c}$ & $2 \mathrm{c}$ \\
Testemunha & $0 \mathrm{f}$ & $0 \mathrm{f}$ & $0 \mathrm{e}$ & $0 \mathrm{f}$ & $0 \mathrm{f}$ & $0 \mathrm{c}$ & $0 \mathrm{c}$ \\
DMS 5\% & 7,2 & 10,0 & 8,30 & 6,37 & 3,67 & 4,24 & 7,94 \\
C.V.\% & 7,14 & 7,30 & 8,38 & 7,63 & 4,67 & 5,36 & 6,31 \\
\hline
\end{tabular}

' - Letra minúscula compara um mesmo herbicida nos diferentes estádios de desenvolvimento.

Estes resultados demonstram que vários herbicidas controlam satisfatoriamente falso-capim-de-rhodes. Isso facilita o manejo químico desta espécie, pois o produtor ou a assistência técnica pode selecionar o composto que tenha menor custo, e ainda, realizar rotação de mecanismos de ação evitando a seleção de biótipos resistentes aos herbicidas.

\section{Terceiro experimento}

Para o glyphosate, houve diferença significativa entre os estádios de desenvolvimento somente aos 6 DAA, onde as plantas com 4 e 8 folhas apresentaram maior toxicidade em relação às plantas com 15 folhas. (Tabela 04). No geral, independentemente do estágio de desenvolvimento, o controle satisfatório por parte deste herbicida ocorreu a partir dos 9 DAA, mantendo-se elevado até 21 DAA.

Estes resultados mostram que o falso-capim-de-rhodes nos estádios de desenvolvimento estudados não é tolerante ao glyphosate. Então, a seleção de falso-capimde-rhodes a campo pode estar ocorrendo pela aplicação de glyphosate em estádios de desenvolvimento superiores, ou pelo uso de sub-doses do produto, ou ainda, por ambos os motivos. No algodão, foi verificado que o glyphosate causou danos severos em folhas de plantas jovens, em relação à plantas mais desenvolvidas (Yamashita \& Guimarães, 2006). Plantas de taboa (Typha subulata) foram mais sensíveis ao glyphosate no estádio de pleno desenvolvimento vegetativo de crescimento em relação ao estádio de pleno florescimento (Silva \& Martins, 2004).

Também o s-metolachor $(576$ e $960 \mathrm{~g}$ $\mathrm{ha}^{-1}$ ) foi eficaz, apresentando $99,75 \%$ de controle. O mesmo foi observado por Freitas et al. (2006) para o controle de A. tenella com o $\mathrm{O}$ quinclorac não mostrou nenhum efeito estimulatório às plantas de falso-capim-derhodes. 
Tabela 04 - Toxicidade dos herbicidas glyphosate e quinclorac em função do estádio de desenvolvimento das plantas de falso-capim-de-rhodes e do período após a aplicação dos herbicidas em relação a testemunha.

\begin{tabular}{|c|c|c|c|c|c|c|c|}
\hline Tratamentos & $3 \mathrm{DAA}$ & $6 \mathrm{DAA}$ & $9 \mathrm{DAA}$ & 12 DAA & 15 DAA & 18 DAA & $21 \mathrm{DAA}$ \\
\hline Glyphosate $4^{1}$ & $27^{\mathrm{ns}}$ & $53 a$ & $87^{\mathrm{ns}}$ & $98^{\mathrm{ns}}$ & $100^{\mathrm{ns}}$ & $98^{\mathrm{ns}}$ & $95^{\mathrm{ns}}$ \\
\hline Glyphosate 8 & 22 & $53 a$ & 83 & 97 & 100 & 98 & 95 \\
\hline Glyphosate 15 & 28 & $33 b$ & 93 & 98 & 100 & 100 & 100 \\
\hline Quinclorac 4 & $18 b$ & $2^{\mathrm{ns}}$ & $2^{\mathrm{ns}}$ & $2^{\text {ns }}$ & $2^{\mathrm{ns}}$ & $2^{\mathrm{ns}}$ & $2^{\mathrm{ns}}$ \\
\hline Quinclorac 8 & $12 \mathrm{c}$ & 7 & 2 & 2 & 2 & 2 & 2 \\
\hline Quinclorac 15 & $28 \mathrm{a}$ & 13 & 5 & 3 & 0 & 0 & 0 \\
\hline DMS $5 \%^{3}$ & 8,9 & 16,63 & 10,96 & 2,73 & 2,62 & 2,37 & 5,24 \\
\hline C.V. $\%^{4}$ & 19,30 & 15,35 & 8,69 & 5,42 & 3,17 & 4,71 & 8,63 \\
\hline
\end{tabular}

'- No estágio "4", "8" e " 15 ", as plantas possuíam 5, 10 e $15 \mathrm{~cm}$ de altura e 4,8 e 15 folhas, respectivamente.

${ }^{2}-{ }^{\mathrm{ns}}=$ não significativo. Letra minúscula compara um mesmo herbicida nos diferentes estádios de desenvolvimento.

3 - DMS 5\%: Diferença mínima significativa.

${ }^{4}$ - Coeficiente de variaçã

Inicialmente, aos 3 DAA, este composto causou maior toxicidade no estágio de desenvolvimento onde as plantas se encontravam com $15 \mathrm{~cm}$ de altura. A partir dos 6 DAA o efeito fitotoxico foi reduzindo e não mostrou diferenças significativas entre os estádios de desenvolvimento (Tabela 04).

\section{Conclusões}

No geral, verificou-se que o falsocapim-de-rhodes nos estádios de
desenvolvimento avaliado não é tolerante ao glyphosate e que no estádio de desenvolvimento inicial os herbicidas atrazine, glufosinate, glyphosate e paraquat apresentam elevado controle e os compostos fluazifop, imazapyr e mesotrione apresentaram controle satisfatório.

\section{Referências}

ALMEIDA, F.S.; RODRIGUES, B.N. Guia de

herbicidas. Instituto Agronômico do Paraná, Londrina, Brasil. 1985. p.309-313.

CHRISTOFFOLETI, P.J. MEDEIROS, D.; MONQUERO, P.A.; PASSINI, T. Plantas daninhas na cultura da soja: controle químico e resistência a herbicidas. In: CÂMARA, G. M. (Ed.) Soja: tecnologia da produção. Piracicaba: ESALQ, 2000. p.179202.

CHRISTOFFOLETI, P.J; LÓPEZ-OVEJERO, R.F.; CARVALHO, J.C. Aspectos da resistência de plantas daninhas a herbicidas. 2. Ed. Campinas: HRAC-BR, 2004. 100 p.

DURIGAN, J.C.; GALLI, A.J. B.; LEITE, G.J. Avaliação da eficiência da mistura de glyphosate e 2,4-D para o controle de plantas daninhas em citros. In: CONGRESSO 
Nunes et al.

BRASILEIRO DE HERBICIDAS E MONQUERO, P.A.; CHRISTOFFOLETI, P.J. PLANTAS DANINHAS, 17., 1988, Dinâmica do banco de sementes em áreas com Piracicaba. Anais... Piracicaba: SBEHD, 1988. aplicação freqüente do herbicida glyphosate. p.303-304.

Planta Daninha, v.21, n.1, p.63-69, 2003.

FLECK, N.G; VIDAL, R.A. Inibidores do fotossistema 2. In: VIDAL, R.A; MEROTTO JR, A. Herbicidologia. Porto Alegre: Evangraf, 2001, p.100-122.

FRANS, R.E.; T ALBERT, R.; MARK, D.; C ROWLEY, H. Experimental design and techniques for measuring and analysis plant responses to weed control practices. In: Research methods in weed science, 3. ed., Southern weed science society, Alabama, 1986. p.29-46.

FUERST, P.; NORMAN, M.A. Interactions of herbicides with photosinthesis electron transport. Weed Sci., v.39, p.458-464, 1991.

KISSMANN, K.G.; GROTH, D. Plantas infestantes e nocivas - Tomo I. São Paulo: BASF, 1992, 797 p.

KOGER, C.H.; REDDY, K.N. Glyphosate efficacy, absorption, and translocation in pitted morningglory (Ipomoea lacunosa). Weed Sci., v.53, p.277-283, 2005.

MARASCHIN, G.E. Manejo de plantas forrageiras dos gêneros Digitaria, Cynodon e Chloris, In: SIMPÓSIO SOBRE MANEJO DA PASTAGEM, 9., 1995, Piracicaba. Anais... Piracicaba: FEALQ, 1995, p.69-99.

MENEZES, V.G et al . Arroz-vermelho (Oryza sativa) resistente aos herbicidas imidazolinonas. Planta Daninha, v.27, n.spe, 2009 .

MEROTTO JR, A. Herbicidologia. Porto Alegre: Evangraf, 2001, p.55-67.

MEROTTO JR, A; FLECK, N.G. Herbicidas inibidores do fotossistema 1. In: VIDAL, R.A;

MONQUERO, P.A.; CHRISTOFFOLETI, P.J.; OSUNA, M.D.; PRADO, R.A. Absorção, translocação e metabolismo do glyphosate em plantas tolerantes e suscetíveis a este herbicida. Planta Daninha, v.22, n.3, p.445-451, 2004.

PETER, B.; WARTENA, M.; KAMPINGA, H.H.; KONINGS, A.W. Role of lipid peroxidation and DNA damage in paraquat toxicity and the interaction of paraquat with ionizing radiation. Biochem. Pharmacol., v.43, n.4, p.705-715, 1992.

RAMOS, H.H.; e DURIGAN, J.C. Avaliação da eficiência da mistura pronta de glyphosate + 2,4-D no controle da Commelina virginica $\mathrm{L}$. em citros. Planta Daninha, v.14, n.1, p.33-41, 1996.

RIZZARDI, M.A.; KARAM, D.; DA CRUZ, M.B. Manejo e controle de plantas daninhas em milho e sorgo. In: VARGAS, L.; ROMAN, E. S. (Eds.) Manual de manejo e controle de plantas daninhas. Bento Gonçalves: Embrapa Uva e Vinho, 2004. p.571-594.

SANTOS, I.C. et al. Eficiência de glyphosate no controle de Commelina benghalensis e Commelina diffusa. Planta Daninha, v.19, p.135-143, 2001.

SILVA, J.R.V.; MARTINS, D. Controle químico de Typha subulata em dois estádios de desenvolvimento. Planta Daninha, v.22, n.3, p.437-443, 2004.

TAMASSIA, L.F.M. et al. Produção e morfologia do capim-de-rhodes em seis maturidades. Scientia Agricola. v.58, n.3, p.125-134. 2001. 
TREZZI, M.M; KRUSE, N.D; VIDAL, R.A. Inibidores de EPSPS. In: VIDAL, R.A; MEROTTO JR, A. Herbicidologia. Porto Alegre: Evangraf, 2001, p.37-45.

VELINI, E. D., et al. Glyphosate. 1. ed. Botucatu: Fepaf, v.1, 2009. 496p.

VIDAL, R. A.; MEROTTO JÚNIOR, A. Herbicidologia. Porto Alegre: Evangraf, 2001. $152 \mathrm{p}$.

YAMASHITA, O.M.; GUIMARAES, S.C.. Deriva simulada de glyphosate em algodoeiro: efeito de dose, cultivar e estádio de desenvolvimento. Planta Daninha, v.24, n.4, 2000 . 